\title{
World Forum for Spine Research: The intervertebral disc
}

\author{
First Japanese Meeting, Kyoto, Japan, 23-26 January 2008
}

\author{
Kenneth M. C. Cheung · Keita Ito
}

Received: 20 July 2008/ Accepted: 20 July 2008/Published online: 13 November 2008

(c) The Author(s) 2008. This article is published with open access at Springerlink.com

Low back pain and intervertebral disc degeneration are the most common reasons for sick leave from work and disability worldwide. To date, the reasons for intervertebral disc degeneration and the cause of back pain remain unsolved, while biological approaches to prevent back pain or reverse disc degeneration are showing promising progress.

The concept of a "World Forum" began with a group of researchers working in this field seeing a need to organize a multidisciplinary meeting that would bring together clinicians, biologists, engineers and scientists working on the intervertebral disc, to share knowledge on the rapid advances in basic, translational and clinical research in this area. The forum would allow faculty and participants to interact, thereby acting as a catalyst to further enhance progress in this field.

With the support of AOSpine, this concept became reality, and the "World Forum for Spine Research, The intervertebral disc" was held in Kyoto, Japan in January 2008. The meeting consisted of invited lectures that gave an overview of aspects of the topic; symposium presentations that gave an in-depth view of an area of interest and free paper and short talk poster presentations that provided an update of the latest scientific research in this field. There

\section{K. M. C. Cheung}

Department of Orthopedics and Traumatology,

The University of Hong Kong Medical Centre,

Queen Mary Hospital, Pokfulam, Hong Kong

e-mail: cheungmc@hku.hk

\section{K. Ito $(\square)$}

Department of Biomedical Engineering,

Eindhoven University of Technology, Den Dolech 2,

WH3.115, Postbus 513, 5600 MB Eindhoven, The Netherlands

e-mail: k.ito@tue.nl were also general poster sessions that allowed participants and faculties to interact and discuss. Over 200 participants from 30 different countries attended the meeting, making this a truly "World Forum". All those that attended agreed that this was one of their "best meeting ever", and the excitement of meeting and sharing information with a group of like-minded individuals could be felt throughout the conference.

One of the themes running through the forum was that of disc regeneration. This began with directing the focus on the ultimate reason why methods for disc regeneration are being developed, i.e. low back pain. Although the large research effort dedicated to disc degeneration and its treatments is motivated by back pain and its high degree of socioeconomic impact, the causative association between back pain and disc degeneration remains speculative but yet generally accepted. This may stem partly from our lack of understanding of back pain. Traditionally, back pain has been viewed as a spinal disorder and attempts to find its source in morphological abnormalities has not been very successful. As our understanding of pain expands, it was suggested that psychosocial aspects of pain should also be included and exploration of that search for functional causes may yield better understanding of the link between degeneration and pain. In this vein, mechanisms of discogenic pain, as investigated in a series of project from one group, were presented. In order to develop treatments which will eventually resolve back pain, it will be very important for us to understand how disc degeneration is functionally transduced to pain. In the near future, as more regenerative strategies are evaluated in vivo and in clinical trials, we should not forget the resolution of back pain as an important end point.

It was agreed that the ultimate goal of regenerating an entire intervertebral disc remains still much in the future 
and that there remain many hurdles to overcome, e.g. complexity of tissue structure and mixtures. One of the major issues limiting the clinical application of biological disc repair was identified as the selection of a suitable cell source. Another issue was the scaffold: what scaffold attributes should be considered, if any scaffold at all, is a biological scaffold a viable option, or how they may be introduced to the disc? Finally, two major in vivo hurdles were debated: is biological disc repair doomed to failure if nutritional limitations are not overcome and can our biological methods withstand the harsh mechanical conditions within the disc as well as providing early recovery of disc biomechanical function? Nevertheless, it was motivating to see that scientists view such aspects more as challenges than hurdles and groups are already growing multiple tissue neo-disc constructs.

While efforts to classically tissue engineer a disc continue, in vivo regeneration strategies were discussed in detail. Molecular, gene and cell therapy strategies each have their unique advantages and disadvantages, but much is unknown about the proper indications, which would make one better suited than another for any particular case. What did become clear though was that all of these biological strategies are geared toward different severities of disc degeneration. Early disease may be more amenable to molecular or gene therapy and with loss of cells of native phenotype with moderate degeneration, cell therapy may have more chances for success. With more severe degeneration, whole or partial biological replacement will certainly be required. With such an emphasis on disease state, it was also obvious that much work is still required to develop diagnostic methods, which are sensitive to detect early stages of disease, some of which were presented at the forum.

This supplement only represents one aspect of the work discussed at the Forum, if the readers are excited by this work; the whole of this meeting is available as a webcast on the AOSpine website (http://www.aospine.org). In addition, the second World Forum for Spine Research meeting is being planned for 2010. Please do look out for announcements soon.

The Editors would finally like to thank all the authors who have contributed to this supplement, as well as all those who participated in the meeting in Japan to make it a success. Special thanks go to the European Spine Journal for providing the opportunity to share these presentations with those in the scientific and medical community who could not attend the forum.

Conflict of interest statement None of the authors has any potential conflict of interest.

Open Access This article is distributed under the terms of the Creative Commons Attribution Noncommercial License which permits any noncommercial use, distribution, and reproduction in any medium, provided the original author(s) and source are credited. 